\title{
AVALIANDO A IMPLEMENTAÇÃO DE UM MODELO DE ATEN- DIMENTO A CRIANÇAS E ADOLESCENTES EM SITUAÇÃO DE RISCO PSICOSSOCIAL ${ }^{1}$
}

\author{
EVALUATING THE IMPLEMENTATION OF A MODEL TO] \\ ASSIST CHILDREN AND ADOLESCENTS AT \\ PSYCHOSOCIAL RISK SITUATION
}

\author{
Marina R. Bazon ${ }^{2}$ \\ Zélia M.M. Biasoli-Alves ${ }^{3}$
}

BAZON, M.R.; BIASOLI-ALVES, Z.M.M. Avaliando a implementação de um modelo de atendimento de crianças e adolescentes em situação de risco psicossocial. Rev. Bras. Cresc. Desenv. Hum., São Paulo, 10(1), 59-69, 2000.

Resumo: Tendo em vista a qualidade dos serviços despendidos a jovens em situação de risco psicossocial, o principal objetivo deste trabalho foi o de analisar a implementação, em contexto brasileiro, de um modelo de intervenção e formação de educadores, denominado Psicoeducação. O programa de uma Casa Abrigo foi focalizado procedendo-se ao estudo através de três etapas: la) Diagnóstico da situação existente, empreendendo-se observações da rotina e entrevistas com os profissionais envolvidos; $2^{\wedge}$ a) Implementação do modelo através da formação continuada; A) Diagnóstico da situação resultante (com novas entrevistas e dando-se seguimento às observações do desenrolar da rotina). A duração total do estudo foi de 15 meses. A análise dos dados mostrou que a situação existente, antes da intervenção, era caracterizada pela assistemática e outros aspectos negativos, corroborando a literatura nacional. Após a intervenção, aspectos relevantes foram alterados contribuindo para uma organização mais condizente com as necessidades da clientela.

Palavras-chave: Crianças/adolescentes; risco psicossocial; formação de educadores; modelo de intervenção; Psicoeducação.

\section{INTRODUÇÃO}

Antes das alterações no Código e na Política Nacional de Assistência Social, educadores e trabalhadores sociais já veiculavam princípios educativos buscando, em vão, transformar a estrutura e o funcionamento dos serviços de atenção à infância, adolescência e às famílias viven- do em situação de alto risco para o desenvolvimento pessoal e social. Contudo, esses esforços isolados para melhorar o trabalho não eram suficientes para desbancar a tradição de práticas assistencialistas e correcionais-repressivas, uma vez que o próprio sistema de administração da Justiça da Infância e da Adolescência contrapunha-se às tentativas de transformação (COSTA, 1994).

1 Trabalho decorrente da Tese de Doutoramento da primeira autora, intitulada Implementação e avaliação de uma proposta de intervenção junto a crianças e adolescentes em situação de risco psicossocial, defendida em 08 de junho de 1999 , junto ao Programa de Pós-Graduação em Psicologia, Faculdade de Filosofia, Ciências e Letras de Ribeirão Preto - Universidade de São Paulo.

2 Professora do Departamento de Psicologia e Educação - FFCLRP - USP, Mestre em Psicoeducação pela Universidade de Montreal/Canadá e Doutora em Psicologia pelo Programa de Pós-Graduação do Departamento de Psicologia e Educação - FFCLRP. Correspondência para: Av. Bandeirantes, 3900 - Monte Alegre - CEP 14040-901- Ribeirão Preto SP. Tel. (0xx16) 602-3830 E-mail: mbazon@ffclrp.usp.br

3 Professora Titular do Departamento de Psicologia e Educação - FFCLRP - USP junto ao Programa de Pós-Graduação em Psicologia. 
Nesta ocasião, “o contexto jurídico existente regulava a qualidade e a quantidade de boa parte dos problemas cotidianos que deveriam ser enfrentados. Ao mesmo tempo, impedia a ampla reprodução de experiências bem sucedidas realizadas em escala reduzida” (MENDEZ, 1994, p. 95).

Com o início do processo de abertura democrática, deflagra-se um amplo movimento social na luta pela defesa dos direitos da criança e do adolescente que irá propiciar mudanças no panorama jurídico, no reordenamento institucional e na melhoria da atenção direta, implicando numa revisão das antigas práticas e na proposição de programas alternativos e diversificados para o atendimento da juventude vivendo em circunstâncias especialmente difíceis (COSTA, 1994).

Nesta linha de transformações, algumas experiências são notificadas no país por terem o mérito de ensaiar, com mais ou menos êxito, a operacionalização dos princípios educativos em alguns serviços de atenção direta à juventude, esboçando diretrizes para a implementação de um novo modelo de atendimento. A revisão dessa literatura (ALVES, 1988; BIERRENBACH, 1987; BROIDE, 1984; DI LORETTO, 1983; FAUSER, GEROLAMO \& MARAZINA, 1989; FIGUEIREDO, 1987; GOMIDE, 1988; GUIRADO, 1980; GUIRADO, 1989; LEITE, 1988), permite destacar, primeiramente, aspectos da dinâmica dos atendimentos com os quais dizia-se necessário romper, num intuito de qualificar a ação:

a. $\mathrm{O}$ distanciamento patente dos técnicos, nos moldes dos atendimentos tradicionais, da realidade cotidiana da instituição, fazendo alusão à "crise da Vigésima Terceira Hora” numa comparação simbólica entre a "uma hora de terapia e as outras vinte e três de vida 'normal'”, nos pátios de uma instituição, questionando o beneficio psicológico prestado à clientela na maior parte do tempo em que a mesma fica sob a guarda da instituição;

b.A ausência de metas a serem alcançadas pelo atendimento dispensado;

c. A confusão metodológica e falta de embasamento dos trabalhadores em geral;

d.A ausência de atividades programadas;

e. A superficialidade das poucas atividades propostas, caracterizando-se por terem um fim em si mesmas e servirem mais para efeito da imagem externa da instituição;

f. A desconsideração da dimensão educativa inerente às atividades de rotina como o despertar, as refeições, as visitas, etc.; g. A ênfase em atividades de profissionalização, sem a prévia adaptação às potencialidades da clientela e sem conexão com o verdadeiro mercado de trabalho;

h. A constante atribuição do fracasso institucional à falta de recursos materiais ("ao sonho irrealizado do computador”) e, paradoxalmente, às dificuldades da própria clientela.

Em seguida, os mesmos autores delinearam princípios que deveriam ser respeitados, a fim de garantir a prevalência de um enfoque educativo pautado no respeito às necessidades dos jovens. Seriam eles:

a. A visão do indivíduo como sujeito, colocando-o na condição de assumir o próprio desenvolvimento/história em mãos, como resultado de um processo educacional amplo (e não como seu ponto inicial). Enquanto sujeitos, os jovens adquiririam uma consciência critica a partir do exame de suas situações concretas de vida, de seus valores culturais e condições institucionais;

b. A expressão do afeto, como mediador das relações e como fator essencial à ocorrência de aprendizagens, impondo, assim, a construção de modelos de atuação cuja tônica seria o atendimento individualizado favorável ao estreitamento das relações, à consolidação de vínculos e ao desenvolvimento da afetividade nos sujeitos;

c. A “com-vivência com a criança” através de atividades do dia a dia, objetivando o "aprender a fazer juntos coisas gostosas", qualificando as relações diretas entre as pessoas, no "corpo a corpo, no aqui e agora” da instituição;

d.A implementação de uma pedagogia compromissada e libertadora, possibilitando a construção de um outro tipo de relacionamento baseado no diálogo e na extinção de mecanismos de dominação, permitindo que sujeitos e profissionais se envolvam e participem ativamente na elaboração das normas de convivência;

e. A reestruturação do ambiente como um todo visando uma organização mais justa e igualitária, erradicando as formas de opressão e alienação presentes nas relações sociais no interior da instituição;

f. A garantia do acesso a instrumentos necessários para o jovem se nortear no mundo e agir sobre ele, implicando num fornecimento de referênciais cognitivos, sociais, afetivos e técnicos, através dos 
quais se possa decodificar e atuar nas situações de sua vida;

g. A consideração do profissional "monitor” enquanto peça fundamental do processo educacional, seja pelo grande número da categoria, ou pela proximidade do contato com a clientela, impondo a necessidade de sua formação como condição imprescindível à qualificação do trabalho na área.

A relevância destas proposições é inegável e, sem sombra de dúvida, elas forneciam pistas para uma trajetória rumo às mudanças no plano jurídico e operacional.

Assim, no início dos anos 90, o "Estatuto da Criança e do Adolescente” (ECA), Lei n 8.069/ 90, é promulgado e, em seguida, a "Lei Orgânica da Assistência Social” (LOAS), Lei nº 8742/93, sendo que, em seus textos, diretrizes gerais para as transformações estruturais no contexto legal e institucional são descritas, sugerindo práticas de atenção direta diferenciadas, em consonância com princípios educativos de promoção do indivíduo e de seus direitos.

As garantias constitucionais básicas para a infância e juventude tornam-se, portanto, reconhecidas e oficializadas, ficando superado o entrave central às transformações desejadas, mas permanecendo, contudo, o desafio de implementar os novos ideais em termos de prática cotidiana dos órgãos executores (MENDEZ, 1994; VASCONCELOS, 1997).

Infelizmente, as observações da realidade atual do atendimento à população em situação de risco fazem concluir que as condições mudaram muito pouco. Embora parte do problema ainda possa ser vinculado à insuficiência ou inexistência de oferta de serviços (MENDEZ, 1994), a dificuldade maior parece residir na implementação de programas que, apesar das inovações veiculadas, geram resultados pouco satisfatórios, podendo-se, ainda, verificar a existência de uma grande desarticulação entre ações empreendidas (GONÇALVES, COSTA \& MARAZINA, 1992; SARTI, 1995; NEVES, 1999; WEBER, 1999; YUNES, FARIA \& TAVARES, 1999).

Na verdade, os equipamentos destinados ao atendimento de crianças e adolescentes foram, em sua maioria, reformulados em aspectos bastante concretos, previstos na Lei. A prática, todavia, não foi absolvida das ações que tendem a “coisificar o sujeito” e transformá-lo em objeto, embora a nova orientação tenha proposto a completa substituição da orientação assistencialista e correcional-repressiva pela implementação de políticas sociais básicas e de assistência social atreladas à noção de direito. Análises do trabalho de linha de frente nos serviços e programas revelam uma justa posição indesejável dos enfoques que têm se alternado nessas diferentes fases da história (COSTA, 1994; MERISSE, 1997; VASCONCELOS, 1997), incorrendo, em última instância, para um atendimento direto à juventude, na linha dos tradicionais orfanatos e reformatórios de outrora, somente com vestígios de um tratamento de caráter social e educacional (JUSTO, 1997).

Neste sentido, é preciso considerar que uma herança foi deixada pelos antigos equipamentos, legando, inclusive, uma boa parte do pessoal que, há anos, vinha atuando na linha da pedagogia do controle e da contenção disciplinar. Dentro desta perspectiva, é possível pensar numa espécie de condicionamento negativo impingido à prática e perpetuado ao longo de muitos anos, que parece impedir a supremacia do enfoque educativo legítimo almejado pelas instituições do "Bem-Estar".

Obviamente, transformações radicais não poderão prescindir de mudanças significativas na estrutura social mais ampla, sem relegar, contudo, a importância de alterações nas relações entre as pessoas, no plano objetivo e subjetivo das interações profissional-clientela, em seus contatos estabelecidos no dia a dia. De acordo com SÊDA (I993), a verdadeira implantação de normas diferenciadas far-se-á no tempo e por intermédio da exposição a novos e bem sucedidos referenciais de ação.

Pode-se dizer que a pesquisa aqui relatada situa-se nesse momento preciso da história da evolução dos serviços de assistência despendidos às crianças e aos adolescentes em situação de risco psicossocial, quando, na busca vigorosa de maior qualidade para a atenção direta, idealiza-se modelos de ação que operacionalizem o enfoque educativo, de promoção do desenvolvimento integral do indivíduo, passíveis de serem reproduzidos numa multiplicidade de contextos de intervenção e face a demandas diversificadas.

Nesta perspectiva, apresenta-se um modelo, elaborado e desenvolvido no Canadá, mais especificamente no Quebec, desde os anos 50, denominado "Psicoeducação" (CARETTE, \& PELLETIER, 1991; GAGNON, 1985; GENDREAU, 1965; GENDREAU, 1966; GENDREAU, 1978; GENDREAU, 1979; GENDREAU, 1993; GENDREAU, MÉTAYER, \& LEBON, 1990; GUINDON, 1960; GUINDON 1969; GUINDON, 1971) que, além de se compatibilizar inteiramente com os princípios estabelecidos pela legislação brasileira, vem se mostrando capaz de contribuir para o avanço do atendimento na área, uma vez que lança luz a uma gama mais ampla de variáveis a serem considera- 
das e estabelece um quadro de referência prática, pautado em experimentações e análises científicas. A denominação Psicoeducação significa, tanto para o Canadá, como para o estrangeiro, uma realidade bastante homogênea, compreendendo uma concepção e uma metodologia da intervenção educativa especializada, um programa de formação de nível superior de educadores (monitores) e uma profissão. É graças a ela que, hoje, o Quebec se beneficia de uma avaliação altamente positiva na área da ação social, reconhecido pela competência que fez evoluir a prática e a concepção da intervenção, em cujos pilares apoiam-se ações sócio-educativas bastante consolidadas e iniciativas que visam melhor responder às necessidades dos jovens (RENOU, 1991; GRÉGOIRE \& LE BLANC, 1995; LE BLANC, MONNE, PROULX, GREGOIRE, \& TRUDEAU-LE-BLANC, 1998).

Embora a Psicoeducação não seja revolucionária no sentido de oferecer soluções mágicas para os problemas de ordem psicossocial, enquanto modelo teórico-prático ela traz instrumentos de reflexão e de sistematização que permitem qualificar programas e o atendimento direto.

De forma sintética, pode-se afirmar que a Psicoeducação dá ênfase à formação de educadores, por intermédio de um aprimoramento no nível do saber, do saber-fazer e do saber-ser. O saber diz respeito a conceitos oriundos de muitas fontes que podem auxiliar no consentimento da clientela e da natureza da intervenção. O saberfazer refere-se à possibilidade de sistematização da prática através do treino nas seguintes operações: observação participante e sistemática, avaliação diagnóstica, planejamento quanto a objetivos de intervenção, organização do meio de intervenção, animação das atividades do cotidiano, utilização educativa dos eventos, avaliação pós-situacional e comunicação. A organização do meio, segundo o modelo, deve ser concebida por intermédio da análise e ajustamento de dez elementos fundamentais, constituintes da realidade na forma de um conjunto estrutural dinâmico, que interagem e influenciam-se mutuamente no sentido de promover ou dificultar as intervenções. São eles: sujeito(s), objetivos, educador(es), programa (conteúdo), métodos didáticos, código e procedimentos, espaço, tempo, sistema de responsabilidades e sistema de avaliação e reconhecimento. Quanto ao saber-ser, este se relaciona às atitudes profissionais do educador diante do "outro”, de suas necessidades e dificuldades.
Com base nessas apreciações, o presente estudo tem como objetivo principal analisar a implementação, em contexto brasileiro, do modelo da Psicoeducação, avaliando, numa primeira instância, aspectos da estrutura e do funcionamento de serviços de atenção direta a jovens considerados em situação de risco, propondo, em seguida, uma formação teórico-prática de educadores, com base nos preceitos Psicoeducação, efetuando por fim uma investigação das manutenções e alterações da situação sob intervenção, bem como da aceitação (e seu nível) das propostas, por parte dos profissionais envolvidos.

\section{METODOLOGIA}

O objeto de estudo deste trabalho foi o programa desenvolvido em uma Casa-Abrigo, da cidade de Ribeirão Preto - SP, mantida por uma Organização Não Governamental (ONG) de cunho confessional, e destinada ao acolhimento de crianças e adolescentes, de ambos os sexos, sob "Medida de Proteção" (ECA, Art 101, inciso VII). Por ocasião do início da coleta de dados, encontravam-se abrigados 15 crianças e adolescentes: 12 crianças, entre 07 e 12 anos, 09 meninos e 03 meninas, e 03 adolescentes, com 14, 15 e 16 anos, sendo 01 menino e 02 meninas. $\mathrm{O}$ tempo de permanência na casa abrigo, foi descrito como bastante variável, podendo-se encontrar crianças ali alojadas há "mais ou menos 05 anos e outras há apenas alguns dias" $\left(\mathrm{Sic}^{4}\right)$.

A Casa-Abrigo funcionava segundo um modelo de família substituta e contava com um casal-larista como referência. Além disso, a equipe regular era constituída por uma assistente social voluntária no papel de coordenadora do projeto, responsabilizando-se inclusive pela intervenção direta com as famílias. Havia uma professora (com magistério), trabalhando num regime de 4 horas/dia, encarregada da atividade de reforço escolar, uma psicóloga cuja tarefa era de orientar a equipe e, eventualmente, a clientela, dispensando 8 horas/sernanais ao serviço. O quadro de funcionários completava-se com uma cozinheira, uma lavadeira e um motorista, havendo ainda um grupo bastante grande de voluntários (12), cuja presença era mais ou menos regular e com papéis diversificados.

De acordo com o enunciado, o objetivo geral do programa consistia em "ajudar as crian-

4 A palavra latina sic será empregada neste trabalho, como manda a definição literal (Novo Dicionário da Língua Portuguesa: “Michaelis”), para indicar que o texto ou a colocação que a antecede está sendo reproduzida do original. Este recurso faz-se necessário uma vez que uma boa parte dos dados de caracterização do serviço em questão provêem de citações espontâneas ou documentos produzidos pelo serviço, sem prévia análise ou confrontação com a realidade. 
ças ali assistidas a se desenvolverem normalmente, apesar de toda história de sofrimento e abandono" (sic).

Na documentação oficial ${ }^{5}$ observou-se uma redação distinta dos objetivos: "Proporcionar às crianças e aos adolescentes participação em atividades educacionais, sociais e recreativas; assistir e apoiar as crianças e os adolescentes, tendo em vista seus problemas familiares, no sentido de resgatar vínculos familiares e uma possivel posterior integração com a família de origem; desenvolver atividades adaptadas às possibilidades físicas e mentais; promover a formação de novos valores, enriquecendo sua auto-estima, visando uma auto-estima saudável e positiva; orientar e acompanhar suas famílias em necessidades básicas, como assistência juridica, internações em clínicas de reabilitação, auxílio material ( $g \hat{e}$ neros alimentícios, móveis, material de construção, etc.)" (sic).

\section{Procedimentos}

Considerando que os objetivos do presente projeto traduziam-se operacionalmente nas tarefas de descrever e comparar o quadro das situações de "antes e depois da implementação do modelo da Psicoeducação", buscando avaliar o aporte trazido por este, optou-se por um trabalho contínuo de observação participante, complementado por entrevistas, em momentos definidos do estudo, com os profissionais envolvidos e pela análise de alguns documentos pertinentes.

O estudo desenvolveu-se seguindo três etapas, cobrindo um período de 15 meses.

Etapa I - O diagnóstico da situação existente visava conhecer o programa levado a efeito na Casa-Abrigo, empreendendo-se entrevistas livres e semi-estruturadas com os profissionais, observações de momentos diversos da rotina institucional, procurando-se identificar padrões de ação e intervenção junto às crianças, adolescentes e suas famílias, e consulta a documentos fornecidos pela entidade.

As entrevistas semi-estruturadas com os oito profissionais em contato direto com a clientela (coordenador, casal-larista, psicóloga, professora, cozinheira, motorista e monitora voluntária) abordavam a concepção do trabalho e do papel profissional, os objetivos, o funcionamento do serviço, as dificuldades encontradas, a percepção da clientela e de seus problemas e a expectativa com relação à formação em Psicoeducação. A duração média dessas entrevistas foi de aproximadamente uma hora cada, e pôde-se contar com o recurso do gravador para o registro das informações.

Etapa II - A formação dos educadores e aplicação do modelo consistiu na implementação da formação teórico-prática dos profissionais envolvidos no atendimento direto à clientela. $\mathrm{O}$ objetivo geral era propiciar-lhes uma nova leitura da realidade de trabalho, segundo os conceitos da Psicoeducação, levando-os, paralelamente, à aplicação do modelo, em termos de análise, planejamento, organização ao meio e intervenção.

Ao longo de toda a etapa (11 meses) buscou-se por uma demonstração concreta de práticas que se entendia adequadas, sob a ótica do modelo, e pelo acompanhamento direto dos profissionais através de supervisões e reuniões de equipe semanais.

A coleta de dados foi através de registro a posteriori das observações participantes, resultando na elaboração de um “diário de campo”, cujo conteúdo envolve uma parte descritiva e outra reflexiva, como sugerido por LUDKE \& ANDRE (1986).

Etapa III - O diagnóstico da situação resultante, realizado através do registro de informações colhidas em uma reunião geral, com 8 horas de duração, e a participação de todos os envolvidos no projeto, realizada com o intúito de discutir e avaliar conjuntamente o processo vivenciado e os resultados obtidos, e também por meio dos dados colhidos com a continuidade das observações participantes na rotina do serviço. Além disso, foram reintroduzidas entrevistas (gravadas) com os profissionais, pautadas nos seguintes temas: $\mathrm{O}$ processo de formação; Comparação entre a rotina do serviço antes e depois da formação; Os aspectos positivos e negativos da formação; Avaliação da formação em termos metodológicos - o dificil e o fácil; A percepção dos resultados; Perspectivas futuras.

Como dado complementar teve-se acesso a outro tipo de documento - o "diário de bordo" produzido pelos profissionais da instituição, em que se achavam registrados os relatos de reuniões de equipe, com discussão de acontecimentos, planejamento de ações, deliberações, encaminhamentos e avaliações de resultados de intervenções.

O Quadro 1 apresenta uma síntese relacionando os procedimentos empregados e os objetivos, para cada etapa do presente estudo.

5 A documentação oficial aqui referida diz respeito à “caracterização do serviço” para registro municipal, enquanto serviço de utilidade pública, “caracterização do serviço” oferecido em resposta à solicitação da promotoria de justiça da infância e juventude, em 1995, e descrição do "Programa do Clubinho” para 1996, formulado em 1995. 


\section{Análise dos dados}

Embora se possa afirmar que um determinado grau de análise tenha sido feito ao longo de toda a investigação, um procedimento analítico mais formal e sistemático aconteceu após a consecução das 3 etapas previstas.
Seguindo fundamentalmente o procedimento proposto por BIASOLI-ALVES \& DIAS DA SILVA (1992), buscou-se por uma apreensão de significados a partir da análise dos dados coletados, iníedigando-os ao contexto em que eles se ingerem, e delnnitando-os através da abordagem conceitual (teoria) adotada como referencial.

Quadro 1 - Síntese dos procedimentos utilizados em relação aos objetivos pretendidos.

\begin{tabular}{|c|c|c|c|}
\hline PERÍODO & ETAPA & PROCEDIMENTOS & OBJETIVOS \\
\hline \multirow[t]{2}{*}{$\begin{array}{l}2 \text { meses e meio } \\
\text { (16 horas semanais } \\
\text { de atuação) }\end{array}$} & \multirow[t]{2}{*}{$\begin{array}{l}\text { I-Diagnóstico } \\
\text { da Situação } \\
\text { Existente }\end{array}$} & $\begin{array}{l}\text { - Entrevistas abertas com o } \\
\text { presidente da entidade, um } \\
\text { membro da diretoria e } \\
\text { educadores da equipe de base; } \\
\text { - Entrevistas semi-estruturadas } \\
\text { com os membros da equipe de } \\
\text { base e voluntários com contato } \\
\text { direto com a clientela; } \\
\text { - Observações de momentos da } \\
\text { rotina do serviço. }\end{array}$ & \multirow[t]{2}{*}{$\begin{array}{l}\text { - Estabelecer contato; } \\
\text { - Conhecer programa levado a } \\
\text { efeito; } \\
\text { - Levantar necessidades do } \\
\text { Clubinho segundo perspectiva } \\
\text { psicoeducativa. }\end{array}$} \\
\hline & & $\begin{array}{l}\text { - análise de documentos oficiais } \\
\text { descrevendo o programa } \\
\text { desenvolvido e o serviço } \\
\text { prestado. }\end{array}$ & \\
\hline $\begin{array}{l}11 \text { meses } \\
\text { (Aproximadamente } \\
24 \text { horas semanais de } \\
\text { atuação) }\end{array}$ & $\begin{array}{l}\text { II - Formação } \\
\text { dos Educadores } \\
\text { e Aplicação do } \\
\text { Modelo }\end{array}$ & $\begin{array}{l}\text { • Observações participantes } \\
\text { (elaboração do "diário de } \\
\text { campo") }\end{array}$ & $\begin{array}{l}\text { - Obter o máximo de dados } \\
\text { relativos ao processo em } \\
\text { andamento. }\end{array}$ \\
\hline \multirow[t]{2}{*}{$\begin{array}{l}\text { (Aproximadamente } \\
6 \text { horas semanais de } \\
\text { atuação) }\end{array}$} & \multirow[t]{2}{*}{$\begin{array}{l}\text { III - Diagnóstico } \\
\text { da Situação } \\
\text { Resultante }\end{array}$} & $\begin{array}{l}\text { - Entrevistas semi-estruturadas } \\
\text { com todos os membros da } \\
\text { equipe; } \\
\text { - Reunião de discussão e } \\
\text { avaliação do projeto com a } \\
\text { equipe e os formadores; } \\
\text { - Observações da rotina do } \\
\text { serviço. }\end{array}$ & \multirow[t]{2}{*}{$\begin{array}{l}\text { - Conhecer a vivência dos } \\
\text { educadores quanto ao processo } \\
\text { de implementação; } \\
\text { - Conhecer o impacto da } \\
\text { aplicação do modelo sobre os } \\
\text { resultados obtidos; } \\
\text { - Verificar transformações no } \\
\text { programa levado a efeito; } \\
\text { - Identificar resultados no plano } \\
\text { do desenvolvimento humano de } \\
\text { crianças e adolescentes } \\
\text { desservidos pelo serviço. }\end{array}$} \\
\hline & & $\begin{array}{l}\text { - Análise do "diário de bordo" } \\
\text { produzido pela equipe do } \\
\text { Clubinho. }\end{array}$ & \\
\hline
\end{tabular}

A análise qualitafivarespaldou-se também num modelo interativo (HUBERMAN \& MILES, 1994), em que se prevê um ciclo indo dos dados de base para as sistematizações, e refazendo-o até a construção de um conjunto mais refinado de significados, sistunatizados na redução.

\section{RESULTADOS}

Os dados obfidos foram organizados seguindo o roteiro propiciado pelos " 10 elementos do modelo da Psicoeducação", e a análise pernufiu fazer considerações, em cada itern, que indicam 
o movimento de transformações desencadeadas na Casa-Abrigo:

\section{1) O mandato institucional e os objetivos de trabalho:}

a. Na la etapa, falta de clareza e de unanimidade dos profissionais implicados ao

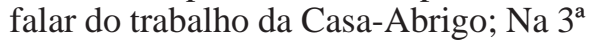
etapa, definições congruentes ou complementares entre si, passando a incluir referências à "promoção do desenvolvimento integral dos sujeitos e resgate dos direitos de cidadania”, ampliando a noção basicamente assistencial do trabalho, com referências quase que exclusivas aos atos de acolher e alimentar, para uma de cunho educativo;

b. Na la etapa, mescla entre mandato institucional e missão religiosa; $\mathrm{Na} 3^{\text {a }}$ etapa, constrição da orientação religiosa a atividades específicas, de cunho confessional;

c. Na la etapa, redução dos objefivos do trabalho à consecução do programa institucional; Na $3^{\mathrm{a}}$ etapa, entendimento do programa como estratégia para a consecução de objefivos;

d.Na $1^{\mathrm{a}}$ etapa, inoperância dos objetivos, dada a generalidade dos mesmos (e.g. "que as crianças se tornem boas pessoas, honestas, trabalhadoras...”); Na $3^{\mathrm{a}}$ etapa, estabelecimento de objetivos claros e específicos, associados à análise das necessidades dos jovens (e.g. "que as crianças consigam cooperar enquanto brmcam...”).

\section{2) A clientela da Casa-Abrigo:}

a. Na la etapa, percepção dos jovens, preponderantemente, pelo prisma das dificuldades ou problemas neles percebidos; $\mathrm{Na}$ $3^{\text {a }}$ etapa, avaliações integradas, abarcando o apontamento de qualidades positivas e potencialidades, belo como o reconhecimento de dificuldades, vistas, em alguns casos como conseqüiência da própria organrzacão e dinâmica institucional;

b.Na Ia etapa, percepção dos jovens como possuidores de caracterisficas estáticas; Na $3^{\text {a }}$ etapa, compreensão da clientela como estando em processo de desenvolvimento, com características próprias a cada etapa do ciclo;

c. Na la etapa, dificuldade em perceber cada sujeito como único em suas características, necessidades e potencialidades; $3^{\text {a }}$ etapa, percepção mais individualizada, demonstrando "enxergar cada qual à sua maneira”, rompendo com a política do "tudo igual pra todo mundo", em que as visões e as ações eram padronizadas, e buscando um melhor ajustamento na forma de lidar com cada criança;

d.Na la etapa, concepção das dificuldades dos sujeitos enquanto entraves ao trabalho a serdesenvolvido; $3^{\mathrm{a}}$ etapa, uma visão dos problemas como componente do "material de trabalho" e, até mesmo, como a parte essencial do acompanhamento despendido na Casa-Abngo.

3) Oprograma desenvolvido na Casa-Abrigo:

a. Na la etapa, um conjunto de afividades pouco estruturado, pobre em número e em qualidade de conteúdo (croché, macramé, ensino bíblico, manicura-pedicura, atividades de rotina, como limpeza e arrumação, etc.), implementado de forma bastante instável, dentro da própria instituição; $3^{\mathrm{a}}$ etapa, uma organização institucional pautada principalmente na estabilização da rotina, em que se prima pela regularidade da programação, verificando-se também a inclusão de novas atividades de conteúdo essencialmente lúdico (brincadeiras em grupos e jogos de sociedade).

\section{4) Os métodos didáticos empregados na Casa-Abrigo:}

a. Na la etapa, filosofia de intervenção inspirada na "rendição de relações familiares", baseada no modelo de “farmília substituta" - calcada na prática do casal-larista; $\mathrm{Na}^{3}$ etapa, uma filosofia de 'promoção do desenvolvimento integral', baseada no estabelecimento de relações significativas e educativas entre adulto-criança e criança-criança, rompendo-se por completo com o modelo anterior;

b.Na la etapa, prática junto aos jovens implementada de forma aleatória, como "ensaio e erro"; Na $3^{\mathrm{a}}$ etapa, ações mais refletidas, pautadas nas observação realizadas na vivência compartilhada;

c. Na la etapa, uma não valorização de eventos da rotina enquanto momentos de aprendizagem para os sujeitos; $\mathrm{Na} 3^{\mathrm{a}}$ etapa, uma "utilização educativa" desses eventos através da"vivência-compartilhada”, "fazendo junto" com o sujeito (limpeza e arrumação da Casa, refeições, brincadeiras, etc.) e não somente monitorando-os. 


\section{5) A organização temporal:}

a. Na la etapa, duração indefinida da medida de abrigo, condicionada às considerações subjetivas quanto a mudanças "na ordem familiar" ou à maioridade e capacidade do sujeito para manter-se financeiramente; $\mathrm{Na}^{\mathrm{a}}$ etapa, estabelecimento de metas claras a serem cumpridas num espaço de tempo determinado, tanto no plano dos sujeitos, quanto no das famílias, abrindo perspectivas para a desinstitucionalização de determinadas crianças;

b.Na $1^{\mathrm{a}}$ etapa, desequilíbrio no dispêndio de tempo entre as atividades existentes no programa, com o favorecimento das de trabalho e de cunho religioso; $\mathrm{Na} 3^{\mathrm{a}}$ etapa, concessão de tempo mais equitativa entre as atividades, fazendo-se acompanhar por uma carga horária também mais equilibrada entre os profissionais com atuação direta na Casa-Abrigo;

c. Na $1^{\mathrm{a}}$ etapa, imprevisibilidade da programação; Na $3^{\mathrm{a}}$ etapa, uma estabilização da rotina dado a esforços no sentido de obedecer uma programação.

\section{6) A organização espacial:}

a. Na $1^{\text {a }}$ etapa, disposição espacial aleatória e, em alguns momentos, com a priorização das necessidades dos adultos-profissionais (como, por exemplo, com a ocupação do melhor cômodo da Casa, em termos de iluminação, ventilação e salubridade, pela administração da entidade mantenedora); $\mathrm{Na}^{\mathrm{a}}$ etapa, uma disposição espacial visando favorecer as vivências de privacidade-intimidade por parte da clientela, e também a vida em grupo (com a orgarnização de uma sala de convivência para os jovens e o estabelecimento de armários privativos para o arranjo de objetos pessoais);

b.Na $1^{a}$ etapa, comunicação e troca com a comunidade reduzida; $\mathrm{Na} 3^{\mathrm{a}}$ etapa, intensificação do intercâmbio, principalmente no que diz respeito: 1 . As famílias de origem das crianças, através do aumento do número de visitas; 2 . Às escolas, com participação freqüente nos eventos sociais propostos pela mesma; 3. À vizinhança, através da freqüentação de jovens colegas do bairro; 4 . Aos recursos da comunidade, pela ampliação no uso de equipamentos comunitárias, sobretudo os relacionados ao lazer (e.g. parques, praças e clubes).

\section{7) $O$ papel do profissional educador:}

a. Na $1^{\mathrm{a}}$ etapa, concepção dos profissionais sobre serem substitutos parentais; $\mathrm{Na}^{\mathrm{a}}$ etapa, eles assumem-se como educadores cujo papel consiste em facilitar o desenvolvimento da criança, mediar sua interação com o ambiente, protegê-las em situações de ameaça à integridade física e psicológica;

b. Na la etapa, valorização de atributos pessoais (vocação) para o trabalho na área; $\mathrm{Na} 3^{\mathrm{a}}$ etapa, crença da necessidade de um aperfeiçoamento profissional, centrado no desenvolvimento de habilidades, tais como observação, iniciativa, firmeza, capacidade para planejar e executar atividades e a comunicação;

c. Na la etapa, exercício do monitoramento da clientela, implicando na vigilância e contenção da mesma; Na $3^{\mathrm{a}}$ etapa, repúdio à prática dessa natureza.

\section{8) As regras de convivência:}

a. Na la etapa, inexistência de um código preestabelecido a ser seguido por todos, predominando as interpretações e maneiras pessoais de lidar com as situações da vida em grupo; Na $3^{\mathrm{a}}$ etapa, padronização inicial de regras de convivência com o ganho de alguma objetividade nas formas de regulação da vida coletiva;

b. Na $3^{\mathrm{a}}$ etapa, constata-se a abertura e manutenção de um espaço para a participação ativa dos sujeitos na construção de regras relacionadas a determinadas situações de vida na Casa-Abrigo, com a introdução de reuniões de grupo regulares tendo como pauta assuntos como a discussão de regras de convivência.

\section{9) Sistema de avaliação e reconhecimento:}

a. Na $1^{a}$ etapa, formas de avaliação dos sujeitos pautadas numa apreciação subjetiva dos mesmos; Na $3^{\text {a }}$ etapa, um princípio de sistematização baseado no critério de consecução de objetivos;

b.Na $3^{\mathrm{a}}$ etapa, as avaliações passam a incluir considerações a respeito da adequação da metodologia empregada pelos profissionais.

\section{0) Sistema de responsabilidades:}

a. Na $1^{\text {a }}$ etapa, atribuição aleatória e compulsória de tarefas aos sujeitos; Na $3^{\mathrm{a}}$ etapa, definição de responsabilidades a serem assumidas pelos mesmos, considerando suas competências e interesses; 
b.Na la etapa, delegação de tarefas preponderante domésticas aos sujeitos, acreditando no caráter intrinsecamente formativo (disciplinador) do trabalho; $\mathrm{Na}$ $3^{\mathrm{a}}$ etapa, tentativa de definir responsabilidades para os sujeitos atreladas a papéis imbuídos de status, poder e liberdade (e.g. "o cuidador das plantas”, “o zelador da sala de T.V.”, “o guardião dos jogos e brinquedos”, etc.).

Extrapolando os elementos previstos pelo modelo Psicoeducativo, um décimo primeiro item pode ser destacado, “a intervenção junto às familias de origem”. Dentro deste contexto, pode-se verificar o seguinte movimento de transformação:

a. Na $1^{\text {a }}$ etapa, visão preponderantemente negativa das famílias de origem; $\mathrm{Na} 3^{\mathrm{a}}$ etapa, uma visão mais integrada, capaz de atribuir aspectos positivos para alguns de seus membros;

b.Na $3^{\text {a }}$ etapa, constata-se a manutenção do caráter predominantemente assistencial e pontual das intervenções, tal qual se verificava na $1^{\mathrm{a}}$ etapa.

\section{CONSIDERAÇÕES FINAIS}

Com base nos resultados é possível afirmar que a instituição, antes da intervenção, caracterizava-se por aspectos bastante negativos de estruturação e funcionamento, indo ao encontro dos apontamentos de falhas feitos pela literatura, referentes à história da atenção direta às crianças e adolescentes em situação de risco. Na verdade, “o diagnóstico da situação encontrada” ( $1^{\text {a }}$ etapa) indicou uma perpetuação dos modelos assistencial e correcional-repressivo, apesar da introdução das novas normas (ECA e LOAS) e dos esforços para melhorar o atendimento tendo em vista um enfoque sócio-educacional.

O modelo da Psicoeducação, por sua vez, mostrou-se válido e eficiente no desencadeamento de mudanças desejáveis, na linha de uma abordagem educativa, de promoção integral do desenvolvimento.

É possível afirmar que os 11 meses de formação teórico-prática dos profissionais na abordagem Psicoeducativa levaram a alterações significativas na organização e no funcionamento da Casa-Abrigo, destacando-se uma estruturação do meio mais sensível às necessidades e características de sua clientela. Vale destacar aquela que talvez possa ser considerada central no processo de mudança institucional desencadeado: a percepção dos adultos relativa às crianças e adolescentes atendidos, que passam a ser vistos como sujeitos em desenvolvimento, apreendidos em suas peculiaridades e subjetividade, creditados de aspectos positivos e de potencial, sendo suas dificuldades e problemas, agora, concebidos como "material para o trabalho de ajuda, consistindo na essência do acompanhamento a ser descendido”. Os outros aspectos apontados parecem, de algum modo, decorrer ou atrelar-se a esse eixo central de transformação.

Mesmo que se levante todos os pontos em que a eficiência do programa implementado foi relativa, não se pode negar que ele veio oferecer respostas bastante concretas às dificuldades identificadas no meio de intervenção e trouxe a possibilidade de os agentes sentirem-se co-participes das deliberações e ações empreendidas. Tal procedimento parece ter facilitado a superacão do limite decorrente da falta de uma formação específica anterior dos profissionais envolvidos no trabalho, eventual obstáculo para o aprofundamento na compreensão e aplicação dos conceitos e técnicas Psicoeducativos, uma vez que permite uma reflexão que vai da vivência concreta para aspectos que transcendem o "aqui e agora” da prática cotidiana.

Não se pode, entretanto, falar de um processo concluído pois denota-se ainda a persistência de "valores e crenças" com as quais buscavase o rompimento, além da necessidade de ajustamento de muitas ações empreendidas. Certa resistência à mudança de determinados padrões de comportamento profissional foi observada. Entretanto, isso não significa que seja imutável.

Neste sentido, há que se considerar o tempo empregado para a implementação do modelo. Os 11 meses de intervenção, numa razão de 24 horas semanais, ainda que longo se comparado aos tradicionais treinamentos efetuados na área, pode não ter sido suficiente para desbancar o condicionamento impingido ao longo de muitos anos.

Assim mesmo, é possível delinear os ganhos trazidos pela abordagem, principalmente ao se enfocar aqueles a quem se destina o serviço, uma vez que as crianças e os adolescentes abrigados passaram a ocupar adequadamente o espaço que lhes fora concedido, tornando-se mais ativos na busca de respostas para suas próprias necessidades e mais participativos da vida institucional, retomando, ainda que parcialmente, suas vidas em mãos, o que, sem dúvida, é a confirmação de que um primeiro e fundamental passo foi concretizado. 


\begin{abstract}
The main theme of this study is the quality of care services for youths in a personal and social risk situation. Its principal aim was to analyze the implementation process, in the Brazilian context, of a model of intervention and care workers' education called Psychoeducation, trying to assess its contribution to the service's organization, the practices and clients. Thus, a home care center's program was analysed. The research procedures were divided into 03 phases: ]) A diagnosis of the situation was carried out, by means of routine observations and interviews with the care workers involved; 2) The model was implemented through continuing education of the youth care workers. The data of this phase were registered through field notes; 3) The iast phase consisted of interviews with the professionals, maintaining the routine observation procedure. The process lasted 15 months. The analyses showed that the situation existing before the intervention was characterized by no systematic practices and other negative aspects, confirming what was pointed out by the national literature: no established objectives, instability in program development, rigid or permissive didactics methods and work with the family only in the assistance levei. After the intervention, important aspects changed: an organization correspondent to clients' needs, program stabilization, introduction of new and richer activities, development of workers' abilities, like acuity observation, and the workers became able to share day-to-day activities in an educational fashion. Also, children and adolescents became more autonomous, able to communicate and presented a positive self-image. But it is necessary to say that old values underlie ali the practices and the expected changes will only be accomplished if there is more time and/or different methods of instruction to the continuous education of youth care workers.
\end{abstract}

Key-words: children/adolescents; psychosocial risk situation; formation of educators; intervention model; psychoeducation.

\section{REFERÊNCIAS BIBLIOGRÁFICAS}

ALVES, J. Uma experiência de educação em meio aberto. Psicologia. Ciencia e Profissão, 8(1): 15-19, 1988.

BIASOLI-ALVES, Z.M.M.; DIAS DA SILVA, M.H.G.F. Análise qualitativa de dados de entrevista: uma proposta. Paidéia, 2(1): 61-69, 1992.

BIERRENBACH, M.I. Instituição fechada e violência: uma visão de dentro. In: SADER, E.; BIERRENBACH, M.I.; FIGUEIREDO, C.R (Orgs.). Fogo no Pavilhão: Uma proposta de liberdade para o menor. São Paulo, Brasiliense, 1987. p. 37-128.

BROIDE, J. Vem. Vem sem FEBEM, vem. Psicologia Atual, 7(38): 17-18, 1984.

CARETTE, J-M; PELLETIER, R Une rétrospective de l'intervention en internat auprès des jeunes. Revue Canadienne de Psycho-éducation, 20(1): 23-28, 1991.

COSTA, A.C.G.d. De menor a cidadão. In: MENDEZ, E.G.; COSTA, A.C.G.d. Das necessidades ao direitos. São Paulo, Malheiros, 1994. Série Direitos da Criança 4: p. 23-45.

DI LORETTO, O. Uma terapia para a criança injustiçada. Psicologia Atual, 6(33): 46-49, 1983.

ECA - Estatuto da Criança e do Adolescente, Lei n 8.069, de 13 de julho de 1990.
FAUSER, A.l.;,GEROLAMO, L.A.; MARAZINA, 1. FEBEM. In: NETO, L.B. e col. (Orgs.). Prática e paixão: memórias e mapas no trabalho com a menor-idade. São Paulo, Oboré, 1989. p. 1 2-38.

FIGUEIREDO, C.P. A questão do menor: uma proposta democrática. In: SADER, E.; BIERRENBACH, M.l.; FIGUEIREDO, C.R (Orgs.). Fogo no Pavilhão: uma proposta de liberdade para o menor. SãoPaulo,Brasiliense, 1987. p. 12-35.

GAGNON, C. Une formation scientifique pour l'éducateur: souhaitable ou nécessaire? Revue Canadienne de Psycho-Éducation, 14(1): 3-9, 1985.

GENDREAU, G. L'utilisation de la réalité dans la rééducation de jeunes délinquant. Revue Canadiense d’Éducation spécialisée, 2: 44-58, 1965.

GENDREAU, G. Boscoville: Une expérience en marche. Conférence présentée au Centre de Formation et de Recherche de l'Éducation Surveillée, Vaucresson, France, 1966.

GENDREAU, G. L'intervention Psycho-Éducative: Solution ou défi? Paris, Fleurus, 1978.

GENDREAU, G. La recherche d'un modèle. Revue Canadienne de Psycho-Éducation, 8(1): 49-55, 1979.

GENDREAU, G. Briser l'isolement entre jeunes en difficulté, éducaterus et parents. Montréal, Sciences et Culture, 1993. 
GENDREAU, G.; MÉTAYER, D.; LEBON, A. L'action psychoéducative: Pour qui? Pour quoi? Paris, Fleururs, 1990.

GOM I DE, P. l . C. A instituição e a identidade do menor infrator.Psicologia: Ciência e Profissão, 8(1): 2022, 1988.

GONÇALVES, R.d.C.; COSTA, S.d.S.G.; MARAZINA, 1. FEBEM. In: NETO, L.B. e col. (Orgs.). Prática e paixão: memórias e mapas no trabalho com a menor-idade. São Paulo, Oboré, 1992. p. 125-157.

GRÉGOIRE, J.; LE BLANC, M. Le modele psychoéducatif. In: ERIEDA - Equipe de recherche pour l'intervention expérimentale différencielle auprès des adolescente en divã culté. (Rapport No. s: la phase de programmation). Montréal, Groupe de recherche sur les adolescente en difficulté, École de Psychoéducation, Université de Montréal \& Centre de Psycho-Éducation dó Québec, 1995.

GUINDON , J. La formation des éducateurs spécislisés à l'institut de psychologie de l’Université de Montréal. La Revue Canadienne de Criminologie, 2(3): 53-60, 1960.

GUINDON, J. Le processus de réeducation du jeune délinquint par l 'actualisation desforces du moi. Montréal, Centre de Recherche en Relation Humaines, 1969.

GUINDON, J. Les étapes de la rééducation des jeunes délinquants...et des autres. Paris, Fleururs, 1971.

GUIRADO, M. A criança e a FEBEM. São Paulo, Perspectiva, 1980.

GUIRADO, M. Instituição e relações afetivas: o vínculo com o abandono. São Paulo, Summus, 1986.

HUBERMAN, A.M.; MILES, M.B. Data management and analysis methods. In: DENZIN, N.K.; LINCOLN, Y.S. (Eas). Handbook of qualitative research. Londres, SAGE Publications, 1994. p. 387-422.

JUSTO, J.S. A institucionalização vivida pela criança de orfanato. In: MERISSE, A.; JUSTO, J.S.; ROCHA, L.C.; VASCONCELOS, M.S. (Orgs.). Lugares da infância: reflexões sobre a história da criança na fábrica, creche e orfanato. São Paulo, Arte e Ciência, 1997. p. 71-92.

LE BLANC, M.; DIONNE, D.; PROULX, J.; GRÉGOIRE, J.C.; TRUDEAU-LE BLANC, $\mathrm{R}$ Intervenir autrement: um modèle différentielpour les adolescents en difficulté. Montreal, Les Presses de l’Université de Montréal, 1998.

LEITE, S.A.d S. Autogoverno: uma alternativa educacional. Psicologia: Ciência e Profissão, 8(1):19, 1988.
LOAS - Lei Orgânica da Assistência Social, Lei n 8742, de 7 de Dezembro de 1993.

LUDKE, M.; ANDRÉ, M.E.D.A. Pesquisa em educação: abordagens qualitativas. São Paulo, E.P.U., 1986.

MENDEZ, E.G. Legislação de “menores” na América Latina: Uma doutrina em situação irregular. In: MENDEZ, E.G.; COSTA, A.C.G.d. Das necessidades ao direito. São Paulo, Malheiros, 1994. Série Direitos da Criança 4: p.86-107.

MERISSE, A. Origem das instituições de atendimento à criança pequena: o caso das creches. In: MERISSE, A. ; JUSTO, J. S. ; ROCHA, L.C. ; VASCONCELOS, M.S. (Orgs.). Lugares da infância: reflexões sobre a história da criança na fábrica, creche e orfanato. São Paulo, Arte e Ciência, 1997. p. 24-51.

NEVES, A.M.S. Crianças abandonadas e institucionalizadas: as especificidades do trabalho com a equipe. Texto \& Contexto -Enfermagem, l(l ): 422-426, 1999.

NEVES, S.M. Psicodramatizando a construção da eidadania. Psicologia: Ciência e Profissão, 16(1): 24-27, 1996.

RENOU, M. La psychoéducation: une critique rétrospective de la conception traditionnelle. Revue Canadienne de Psycho-Éducation, 20(2):151-167, 1991.

SARTI, C.A. A continuidade entre a casa e a rua no mundo da criança pobre. Revista Brasileira Crescimento e Desenvolvimento Humano, 5(1/2): 3947, 1995. (Trabalho apresentado na XIX Reunião Anual da ANPOCS, 1995).

SÊDA, E. Construir o passado - ou como mudar hábitos, usos e costumes, tendo como instrumento o Estatuto da Criança e do Adolescente: Série direitos da criança 2. São Paulo, Malheiros,1993.

VASCONCELOS, M. S. Os orfanatos e a ideologia da reintegração. In: MERISSE, A.; JUSTO, J.S.; ROCHA, L.C.; VASCONCELOS, M.S. (Orgs.). Lugares da infancia: reflexões sobre a história da criança na fábrica, creche e orfanato. São Paulo, Arte e Ciência, 1997.p.6-23.

WEBER, L.N.D. A ficção e a realidade de crianças institucionalizadas: uma proposta de intervenção. In: CONGRESSO INTERNACIONAL FAMILIA E VIOLÊNCIA. Texto e Contexto, Florianópolis, 1999. p.427-430.

YUNES, M.A.M.; FARIA, L.C.; TAVARES, F.A. As instituições como contexto de desenvolvimento de crianças em situação de rua da cidade de Rio Grande-RS. In: XX X X REUNIÃO ANUAL DE PSICOLOGIA, CAMPINAS, Resumos de Comunicação Cienti^Sca. Ribeirão Preto, SBP, 1999. p.122- 123.

Recebido em 08/03/2000 Aprovado em 30/05/2000 